yellowish mass and its characteristic change of appearance when submerged in water to a villous sea anemone-like tumor suggests the diagnosis of papillary fibroelastoma. However, the definitive diagnosis is confirmed by histopathologic examinations after surgery.

\section{CONCLUSIONS}

We present an exceptional case of a papillary fibroelastoma originating from the aortic wall of the noncoronary sinus. The patient was successfully managed with a valvesparing procedure. No aortic regurgitation was detected postoperatively.

\section{References}

1. Gopaldas RR, Atluri PV, Blaustein AS, Bakaeen FG, Huh J, Chu D. Papillary fibroelastoma of the aortic valve: operative approaches upon incidental discovery. Tex Heart Inst J. 2009;36:160-3.

2. Washiyama N, Yamashita K, Terada H, Ohkura K, Akuzawa S. Surgical treatment of papillary fibroelastoma of the aortic valve: a case report. Ann Thorac Surg. 2010;16:297-300

3. Yerebakan C, Liebold A, Steinhoff G, Skrabal CA. Papillary fibroelastoma of the aortic wall with partial occlusion of the right coronary ostium. Ann Thorac Surg. 2009;87:1953-4.

4. Jha NK, Khouri M, Murphy DM, Salustri A, Khan JA, Saleh MA, et al. Papillary fibroelastoma of the aortic valve-a case report and literature review. J Cardiothorac Surg. 2010;17:84.

5. Bicer M, Cikirikcioglu M, Pektok E, Müller H, Dettwiler S, Kalangos A Papillary fibroelastoma of the left atrial wall: a case report. J Cardiothorac Surg. 2009;4:28.

\title{
Open transcatheter tricuspid balloon expandable valve-in-valve implantation for failed bioprosthesis
}

\author{
Gino Gerosa, MD, ${ }^{\mathrm{a}}$ Augusto D'Onofrio, MD, ${ }^{\mathrm{a}}$ Chiara Tessari, MD, ${ }^{\mathrm{a}}$ Demetrio Pittarello, MD, \\ Maurizio Rubino, $\mathrm{MD},{ }^{\mathrm{a}}$ and Andrea Colli, $\mathrm{MD}, \mathrm{PhD},{ }^{\mathrm{a}}$ Padua, Italy
}

Transcatheter valve-in-valve replacement is a reliable therapeutic option for degenerated bioprosthetic heart valves in high-risk patients. Successful transfemoral and transapical techniques have been described for aortic, mitral, and pulmonary bioprostheses. To the best of our knowledge, few cases of transcatheter valve-in-valve tricuspid valve implantation have been reported. ${ }^{1-3}$

Van Garsse and colleagues ${ }^{1}$ described the deployment of the prosthesis via the right internal jugular vein with ventricular pacing under cardiopulmonary bypass (CPB) support via peripheral cannulation. Weich and colleagues ${ }^{2}$ and Cerillo and colleagues ${ }^{3}$ delivered the device via the right internal jugular vein without ventricular pacing.

Hon and colleagues ${ }^{4}$ and Cheung and colleagues ${ }^{5}$ delivered the transcatheter prosthesis via a right thoracotomy and direct puncture of the right atrium. We present a case of an "open" transcatheter valve-in-valve replacement in a highrisk patient who required conventional cardiac surgery for severe dysfunction of the aortic, mitral, and tricuspid heart

\footnotetext{
From the Division of Cardiac Surgery, ${ }^{\text {a }}$ Department of Cardiac, Thoracic, and Vascular Sciences, and Institute of Anesthesia, ${ }^{\mathrm{b}}$ University of Padua, Padua, Italy. Disclosures: Authors have nothing to disclose with regard to commercial support.

Received for publication March 14, 2013; accepted for publication March 19, 2013; available ahead of print April 15, 2013.

Address for reprints: Andrea Colli, MD, PhD, Division of Cardiac Surgery, Department of Cardiac, Thoracic and Vascular Sciences, University of Padua,

Via Giustiniani, 2, 35127 Padova, Italy (E-mail: colli.andrea.bcn@gmail.com).

J Thorac Cardiovasc Surg 2013;146:e3-5

0022-5223/\$36.00

Copyright (C) 2013 by The American Association for Thoracic Surgery

http://dx.doi.org/10.1016/j.jtcvs.2013.03.034
}

valves with a high frailty of right-sided heart structures because of twice passed tricuspid valve replacement.

\section{CLINICAL SUMMARY}

The patient is a 66-year-old woman with rheumatic heart disease who underwent tricuspid valve replacement with a bioprosthesis (Hancock Medtronic, $27 \mathrm{~mm}$; Medtronic Inc, Minneapolis, Minn) at 25 years of age. She underwent reoperation at 39 years of age, and the calcified tricuspid bioprosthesis was replaced with a new bioprosthesis (Hancock Medtronic, $29 \mathrm{~mm}$ ) plus mitral commissurotomy. Six years later, she underwent percutaneous mitral valvuloplasty for recurrence of mitral stenosis. At that time, oral anticoagulation was begun for the onset of permanent atrial fibrillation.

During the past 4 years, her clinical condition worsened with shortness of breath and several hospital admissions for congestive heart failure despite optimal medical treatment. Transthoracic echocardiography revealed normal left ventricular systolic function, left and right atrium dilatation, a calcified tricuspid bioprosthesis with moderate stenosis (mean gradient $11 \mathrm{~mm} \mathrm{Hg}$ ), severe regurgitation, moderate mitral valve stenosis (mean gradient, $6 \mathrm{~mm} \mathrm{Hg}$ ), severe regurgitation, and moderate aortic valve stenosis (valve area, $0.66 \mathrm{~cm}^{2} / \mathrm{m}^{2}$ ).

A decision was made to replace the tricuspid bioprosthesis and the mitral and aortic valves. The European System for Cardiac Operative Risk Evaluation I was $31.55 \%$, and European System for Cardiac Operative Risk Evaluation II was $36.73 \%$. The patient underwent conventional cardiac surgery through a median resternotomy, $\mathrm{CPB}$, and 

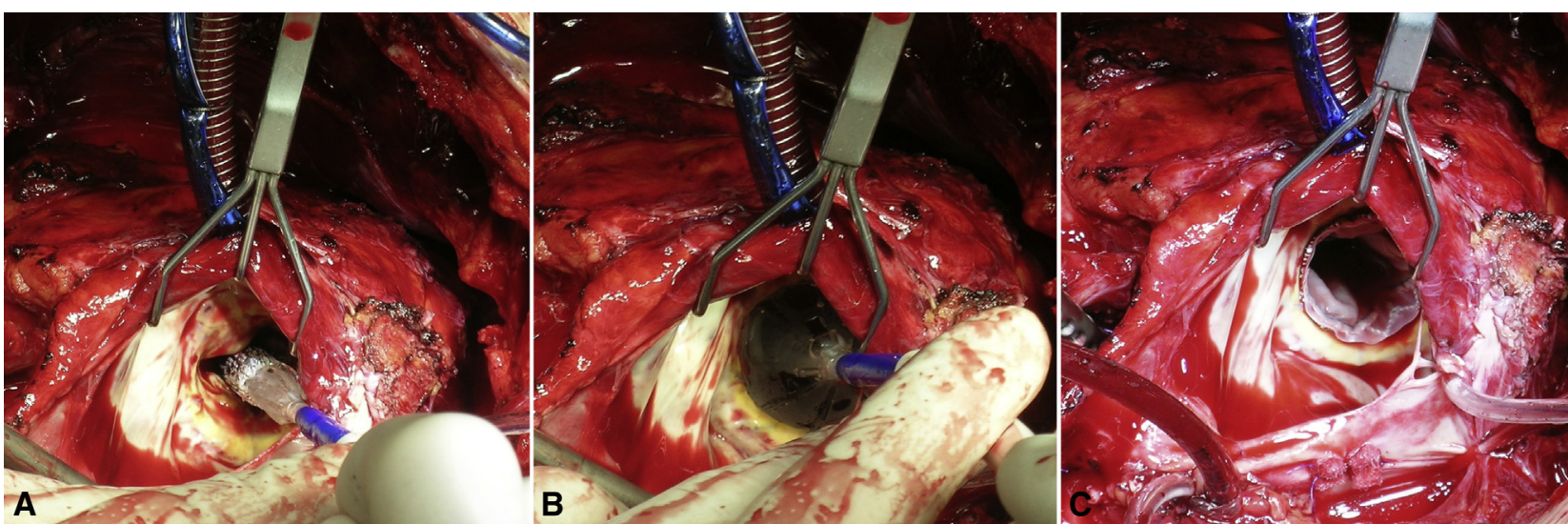

FIGURE 1. Surgical field. Open transcatheter tricuspid balloon expandable valve-in-valve implantation for failed bioprosthesis. A, Position of the Edwards Sapien XT valve $29 \mathrm{~mm}$ crimped on the balloon of the transcatheter delivery system (Ascendra; Edwards Lifesciences, Irvine, Calif) through the failed tricuspid bioprosthesis. B, Balloon inflation and valve positioning. C, Final result of valve-in-valve position.

cardioplegic arrest. She received an aortic mechanical prosthesis (St Jude Regent size 19; St Jude Medical Inc, St Paul, Minn), a biological mitral prosthesis (Biocor Epic size 31; St Jude Medical Inc), a transcatheter valve-in-valve Edwards Sapien XT (size 29; Edwards Lifesciences, Irvine, Calif) in the tricuspid position (Figure 1), and a reconstruction of the superior vena cava with a Dacron prosthesis $(12 \mathrm{~mm})$.

The Sapien XT prosthesis was mounted on the transapical delivery system (Ascendra; Edwards Lifesciences) in a normal orientation and implanted under direct vision inside the previously implanted tricuspid valve prosthesis (Figure 1). The deployment was uneventful, and transesophageal intraoperative echocardiography revealed a wellanchored device with no paravalvular leaks. The mean gradient across the valve was $3 \mathrm{~mm} \mathrm{Hg}$ (Figure 2). CPB time was 420 minutes, and aortic crossclamp time was 194 minutes.

\section{DISCUSSION}

We present the first successful open surgery under direct vision tricuspid valve-in-valve implantation. The decision to implant the transcatheter prosthesis via open surgery was made because of the presence of a particular frail right atrium and superior vena cava that required reconstruction with a Dacron prosthesis and a consequent frail tricuspid annulus that made third-time conventional replacement technically challenging and at high risk of late paravalvular leak. The device was slowly deployed under direct vision with partial inflation of the inner balloon to stabilize the valve.

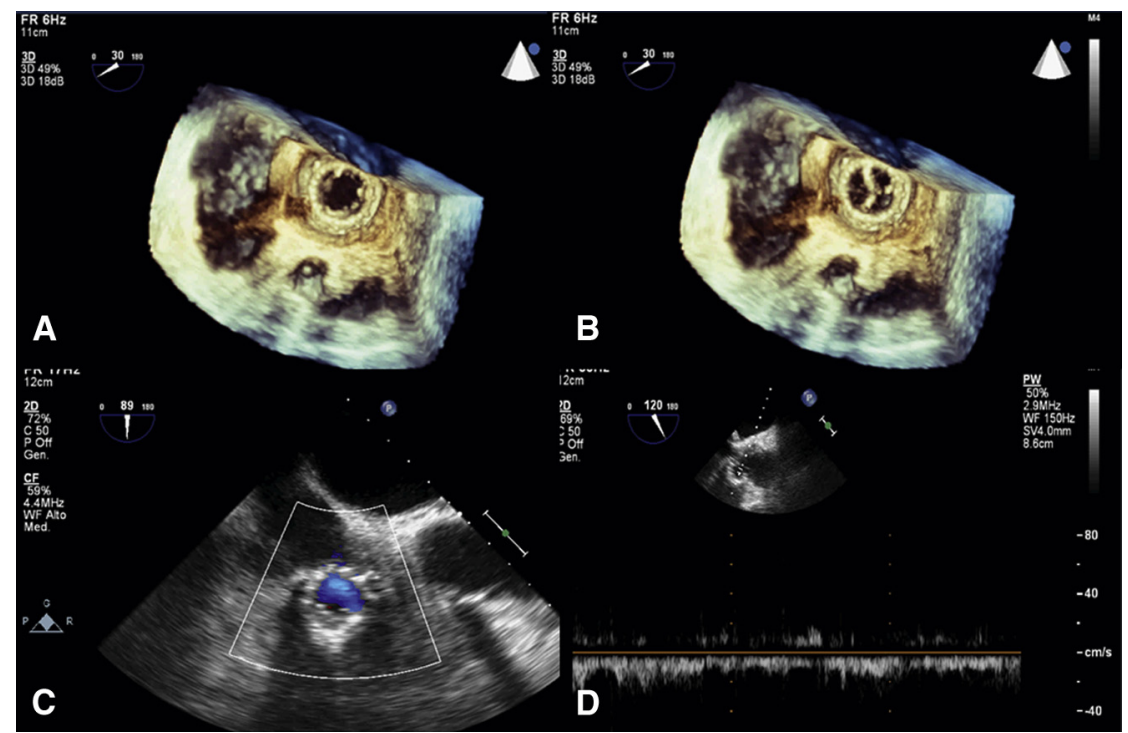

FIGURE 2. Live 3-dimensional transesophageal echocardiography. A, Adequate opening of the tricuspid valve-in-valve bioprosthesis. B, Adequate closure of the tricuspid valve-in-valve bioprosthesis. C, Color Doppler showing adequate position and function of the tricuspid valve-in-valve bioprosthesis without paravalvular leaks. D, Postprocedure pulsatile Doppler of the tricuspid valve-in-valve bioprosthesis confirming a normal hemodynamic pattern. 
At this point, full inflation of the balloon was performed with good expansion and anchoring of the device. Further development of shorter-delivery catheters will facilitate this intervention.

\section{CONCLUSIONS}

This patient presented a special combination of surgical challenging problems, and it is unlikely that this approach will become widely used; however, if indicated, the approach is feasible and reproducible, and provides reliable results.

\section{References}

1. Van Garsse LAFM, ter Bekke RMA, van Ommen VGVA. Percutaneous transcath eter valve-in-valve implantation in stenosed tricuspid valve bioprosthesis. Circulation. 2011;123:e219-21.

2. Weich H, Janson J, van Wyk J, Herbst P, le Roux P, Doubell A. Transjugular tricuspid valve-in-valve replacement. Circulation. 2011;124:e157-60.

3. Cerillo AG, Berti S, Glauber M. Transjugular tricuspid valve-in-valve implantation: a safe and effective approach. Ann Thorac Surg. 2011;92:777-8.

4. Hon JKF, Cheung A, Ye J, Carere RG, Munt B, Josan K, et al. Transatrial transcatheter tricuspid valve-in-valve implantation of balloon expandable bioprosthesis. Ann Thorac Surg. 2010;90:1696-7.

5. Cheung A, Soon JL, Webb JG, Ye J. Transatrial transcatheter tricuspid valve-invalve technique. J Card Surg. 2012;27:196-8.

\title{
Endovascular closure of Potts shunt before double lung transplantation for idiopathic pulmonary arterial hypertension
}

\author{
Marina Paradela, MD, Olaf Mercier, MD, PhD, Alban Baruteau, MD, and Elie Fadel, MD, PhD, \\ Le Plessis-Robinson, France
}

Potts shunt has been performed in children with severe idiopathic pulmonary arterial hypertension (iPAH) as a palliative treatment of right ventricular failure. ${ }^{1}$ This procedure consists of a direct side-to-side anastomosis between the left pulmonary artery and the descending aorta. It creates a similar hemodynamic condition to Eisenmenger's syndrome with an immediate clinical improvement, but the disease process is unaffected. Indeed, lung or heart-lung transplantations remain the ultimate treatment if the condition worsens. ${ }^{2,3}$ Before transplantation, closure of the Potts anastomosis is required to allow the surgical procedure. We report a case of iPAH treated by Potts shunt that had been closed with an aortic endovascular stent-graft before double lung transplantation (DLTx).

\section{CLINICAL SUMMARY}

A 14-year-old girl with a history of iPAH was referred to the Marie Lannelongue Hospital for DLTx. She was diagnosed at 6 years of age and initially treated with bosentan and epoprostenol. Two years later, she presented with

\footnotetext{
From the Department of Thoracic and Vascular Surgery and Heart-Lung Transplantation, Marie Lannelongue Hospital, Paris-Sud University, Le Plessis-Robinson, France.

Disclosures: Authors have nothing to disclose with regard to commercial support. Received for publication Dec 16, 2012; revisions received March 10, 2013; accepted for publication March 18, 2013; available ahead of print April 8, 2013.

Address for reprints: Olaf Mercier, MD, PhD, Department of Thoracic and Vascular Surgery and Heart-Lung Transplantation, Marie Lannelongue Hospital, 133 Ave de la Résistance, 92350 Le Plessis-Robinson, France (E-mail: o.mercier@ccml.fr). J Thorac Cardiovasc Surg 2013;146:e5-7 $0022-5223 / \$ 36.00$

Copyright (c) 2013 by The American Association for Thoracic Surgery http://dx.doi.org/10.1016/j.jtcvs.2013.03.020
}

a dyspnea New York Heart Association (NYHA)/World Health Organization (WHO) functional class IV. She was treated using a Potts shunt through a left thoracotomy without cardiopulmonary bypass (CPB). The patient recovered NYHA/WHO functional class II and was weaned from epoprostenol.

Six years later, an episode of massive hemoptysis developed in the patient. A thoracic contrast-enhanced

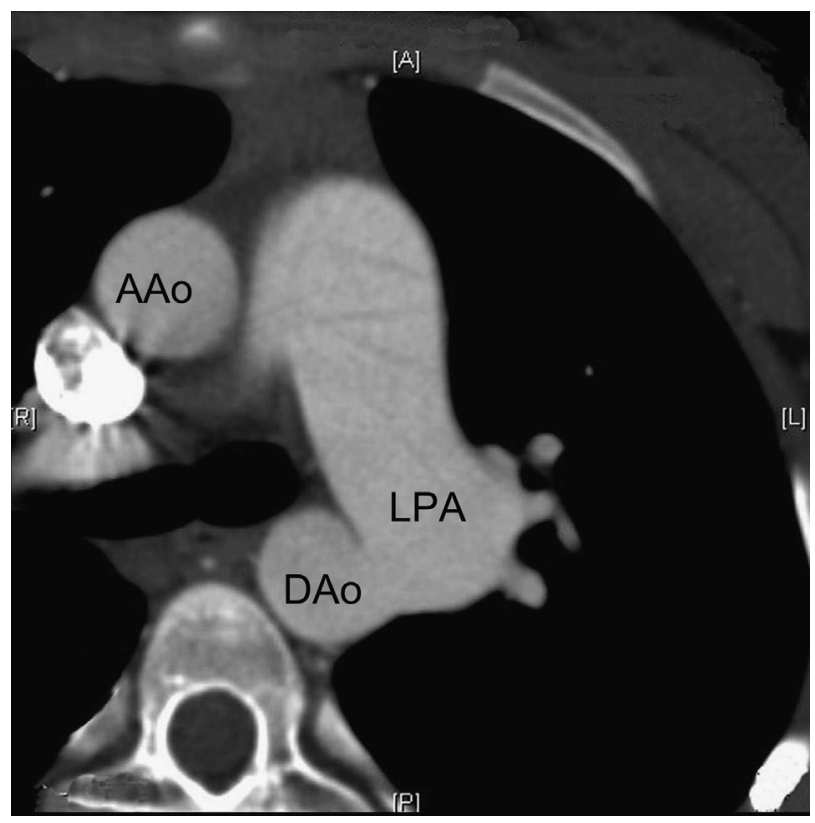

FIGURE 1. Thoracic computed tomography showing the patent Potts shunt, ascending aorta, descending aorta, and left pulmonary artery. $A A o$, Ascending aorta; $L P A$, left pulmonary artery; DAo, descending aorta. 